\title{
Design of installation for preparation of food chitosan from crab shell containing raw material by electrophysical processing
}

\author{
Glotova Irina \\ Faculty of Technology and Merchandizing \\ Voronezh State Agrarian University \\ Voronezh, Russia \\ glotova-irina@yandex.ru \\ Galochkina Nadezhda \\ Faculty of Technology and Merchandizing \\ Voronezh State Agrarian University \\ Voronezh, Russia \\ Yarovoy Mikhail \\ The Faculty of Rural Engineering \\ Voronezh State Agrarian University \\ Voronezh, Russia \\ Maksimov Igor \\ Faculty of Technology and Merchandizing \\ Voronezh State Agrarian University \\ Voronezh, Russia
}

\author{
Balabaev Vladimir \\ Faculty of Technology and Merchandizing \\ Voronezh State Agrarian University \\ Voronezh, Russia
}

\author{
Shakhov Sergey \\ Limited Liability Companyline «SAN» \\ Voronezh, Russia
}

\author{
Korolkova Nadezhda \\ Faculty of Technology and Merchandizing \\ Voronezh State Agrarian University \\ Voronezh, Russia
}

\author{
Kubasova Anna \\ Faculty of Technology and Merchandizing \\ Voronezh State Agrarian University \\ Voronezh, Russia
}

\begin{abstract}
Traditional technologies of chitosan producing may negatively affect the main quality parameters of chitosan (molecular weight, the degree of deacetylation) due to hard alkali-acid treatment of raw materials. The authors propose an alternative technical approach. It involves the use of electrohydraulic shocks, which use extra-long bits. For reproduction of the electrohydraulic shocks in the volume of the compound, consisting of the shell of crustaceans and water in the ratio of $1: 15$, the authors used the installation which transforms the source of energy by means of the condenser as the accumulator of electrical energy. This scheme is implemented in the original technical solution of the apparatus for producing chitin and chitosan. The processing of shell crustaceans is advantageous when carried out with an average mode of operation of the electro-hydraulic setup, the capacitance of the capacitor $(C)=0.1 \mu f$; voltage $U=50 \mathrm{kV}$; the distance between electrodes $(\mathrm{l})=25 \mathrm{~mm}$; the temperature of the mixture $(t)=20$ ${ }^{\circ} \mathrm{C}$. The resulting suspension is passed through a suction filter, the precipitate is placed in the reactor with a mixer and a shirt. The precipitate is treated with hydrochloric acid with volume fraction of $2-4 \%$ with the hydraulic module of $1: 10$, a temperature of $20-25{ }^{\circ} \mathrm{C}$ and stirring for $2 \mathrm{~h}$. Further, the solid and the liquid fractions were separated. Depending on the kind of
\end{abstract}

used shell crustaceans, next a solution of sodium hydroxide with a mass fraction of $35-45 \%$ was added to the obtained chitin and the mixture was incubated at a temperature of $95-98^{\circ} \mathrm{C}$ during 1 2 hours. The proposed approach has the following advantages: the stages of grinding and deproteinization of the raw materials are combined, the additional use of alkali is excluded at the stage of deproteinization.

Keywords-chitin, chitosan, electro-shocks, the degree of deacetylation, shrimp shell

\section{INTRODUCTION}

An actual problem at the present stage of the development of engineering and technology is the safety of biological systems. This problem is directly linked to the health of the person in modern conditions, which are characterized by unfavorable environmental conditions over large areas, pollution from human waste, especially waste of polymeric materials.

The most important task facing the food industry - the preservation and maintenance of human health through 
nutrition. Another important task is to ensure the safety and sustainability of products and industries, which is to develop effective and efficient ways for processing of the secondary resources sector of agriculture. Perspective raw material for the solution of tasks is a natural biopolymer - chitosan [1-4]. This polymer has many unique properties: high biological activity and compatibility with the tissues of humans, animals and plants; it does not pollute the environment because it is destroyed by enzymes of microorganisms and can be widely applied in environmental protection $[5,6]$.

The issues of intensification of processes for the production of structural biopolymers - chitin and chitosan, occupy a central place in the works of domestic and foreign researchers $[2,6,7]$. This trend reflects the global direction of development of all processing industries, including food and pharmaceutical production. The traditional technology of obtaining the chitosan involves the use of the shell crustaceans. The main role in the traditional technologies belongs to the transfer of the matter from one phase to another.

The technology of obtaining the chitosan from chitincontaining raw material includes the following main stages: grinding of raw materials; removing the protein fractions (deproteinization); translation the mineral components of raw materials in the soluble form (demineralization); deacetylation of chitin with obtaining the chitosan.

The priorities in this area are the technological solutions that reduce the consumption of aggressive reagents at the stage of the deproteinization of the shell crustaceans. For example, the replacement of the sodium hydroxide solution by the ammonium hydroxide solution is allowed to obtain the volatile components as the reaction products [8]

The purpose of the work is to develop the technique and technology of obtaining food chitosan with the use of the electrophysical processing of chitin-containing raw materials of the crustaceans.

\section{MATERIALS AND METHODS}

The authors used crab shell, containing raw material (SCRM), obtained in the industrial processing of freshwater crayfish, Arctic shrimp (Ledovo Company., Schelkovo, Moscow region). The catch season was from March to October 2015. Shrimps were caught in the Okhotsk Sea (the Far East fishery basin).

The authors received and investigated the experimental samples of chitosan in the laboratory of Technology and Merchandizing Faculty in Voronezh State Agricultural University from April to December 2015.

The fluorimetric study of chitosan substances was carried out in the laboratory of Institute of Cell Biophysics of the Russian Academy of Sciences (Pushchino, Moscow region) in May, 2015.

The quality of the obtained chitosan was adjusted by a number of indicators. The content of minerals was established by dry ashing.
The molecular weight of chitosan was determined by a standard viscometric method. The measurements were carried out at $250{ }^{\circ} \mathrm{C}$ in a capillary viscometer Ubbelohde, the diameter of which is equal to $0.54 \mathrm{~mm}$. A sample of chitosan was previously dispersed in succinic acid. Calculation of molecular weight was carried out according to the equation of Mark-Kuhn-Houwink [7].

The degree of deacetylation was determined by potentiometric titration on universal ionometer EV-74 using a glass electrode. The method is based on the titration of the chloride hydrogen connected with a molecule of chitosan. The researches were carried out by the titration of solution of a chitosan by the sodium hydroxide solution.

Microbiological parameters were determined according to standard procedures.

The comparative evaluation of structural changes of products of chitin-containing raw material subjected to various types of preliminary treatment with chemical reagents was carried out with the use of a method of IR-spectroscopy [8]. The IR spectra of chitosan are removed on the spectrophotometer Vertex 70 (Bruker, Germany) in the range of $4000-400 \mathrm{~cm}^{-1}$. The preliminary works were conducted by drawing a thin film of a sample on a silicon substrate.

Spectral properties of chitosan dispersions and films were studied using the fluorescent double-beam scanning spectrophotometer PERKIN ELMER Lambda 800. We recorded the fluorescence spectra at $20{ }^{\circ} \mathrm{C}$ in a mirrored cuvette with optical path length $1 \mathrm{~cm}$ in the range of 400-550 $\mathrm{nm}$ (upon excitation at $370 \mathrm{~nm}$ ) and 430-500 $\mathrm{nm}$ (upon excitation $380 \mathrm{~nm}$ ). The light-transmitting slit was set at 8 $\mathrm{mm}$. The samples for fluorescence studies containing chitosan and hydrophobic dye with the concentration of $1 * 10^{-6}$ $\mathrm{mol} / \mathrm{dm}^{3}$, were incubated for $2-3$ hours at $20^{\circ} \mathrm{C}$. Fluorescence ranges of dye solutions and chitosan containing compositions were subtracted from the fluorescence spectra of the samples. In determining the degree of polarization we used the wavelength of excitation $380 \mathrm{~nm}$ and emission of $430 \mathrm{~nm}$.

The magnitude of light scattering was measured on a spectrofluorimeter, similar to the previous tech experience (in the mirror cells) in the crossed monochromators at the same wavelength of $560 \mathrm{~nm}$ (slit of $8 \mathrm{~nm}$ in the first monochromator and $1 \mathrm{~nm}$ in the second). The channel got ambient light in proportion to the size of the particles and their number. .

Chitosan films were prepared from chitosan substances with the addition of 1-aniline-8-naphthalenesulfonate (ANS) with a concentration of $1.56 * 10^{-6} \mathrm{~mol} / \mathrm{dm}^{3}$ by the method of spreading on the glass substrate with subsequent evaporation of the acid in the air. The films were kept to evaporation of the acid at the ambient temperature for $36-48 \mathrm{~h}$. During the study, the films were deposited on cover glasses and placed in a glass cuvette diagonally. Fluorescence spectrum was removed in the range of 430-500 $\mathrm{nm}$, with the excitement wavelength of $310 \mathrm{~nm}$. The light-transmitting slit size was set to be $5 \mathrm{~nm}$ for excitation and $2.5 \mathrm{~nm}$ - for emission. 


\section{RESULTS AND DISCUSSION}

An analysis of the patenting of developments in the areas of application of chitosan shows a significantly increased interest in it and demand for medicine, pharmaceutics, chemical and food industries (Fig.1). At the same time, Russia is not yet among the leading countries in the production of chitosan. (Fig. 2)

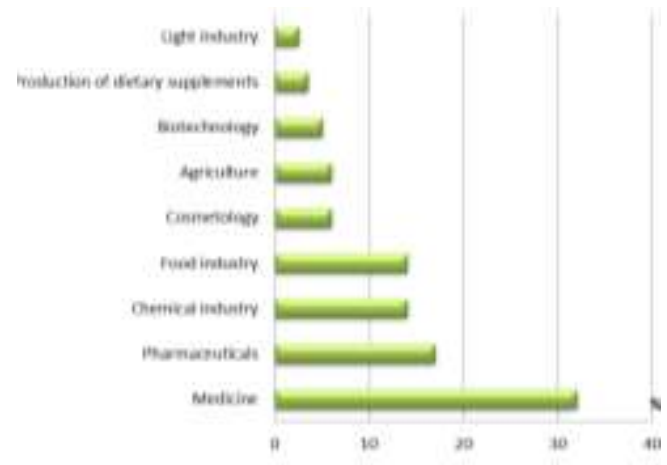

Fig. 1. Percentage of OIC using chitosan by field of application

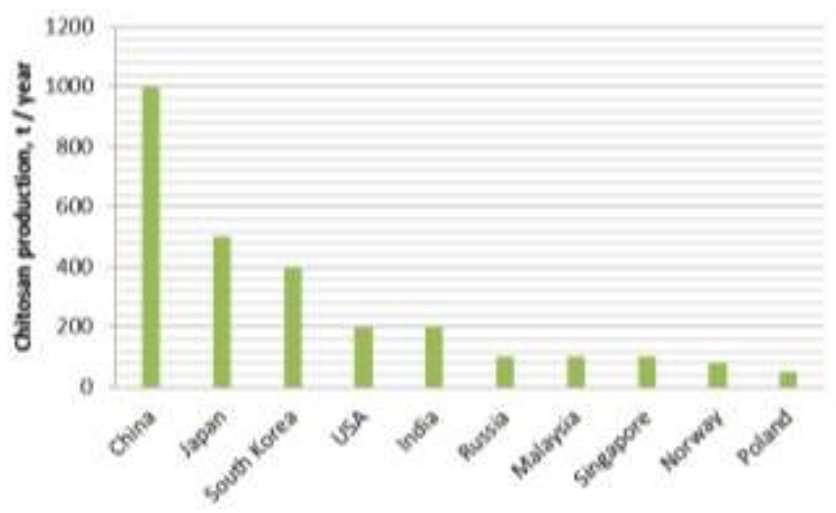

Fig. 2. Data on production volumes of chitosan as of 2016

To increase the production and consumption of chitosan in the food industry, it is important to evaluate the technological efficiency in the use of alternative raw materials - shells of freshwater crayfish, shrimps, industrial waste recycling of oyster mushroom for production food chitosan and for its appropriate dosage with the composition of meat stuffing.

The process of allocation of chitin and chitosan was preceded by a general analysis of the chemical composition of raw materials (table 1). The next stage of the study was the determination of the mass fraction of chitin in raw materials of animal and vegetable origin (table 2). Chitin refers to insoluble polymers; therefore, for its separation from the fruiting bodies of mushrooms, crabs and shrimp, one needs a consistent and complete removal of protein and mineral parts of the material - deproteinization (DP) and demineralization (DM).

The release of chitosan from various raw material sources was carried out in accordance with the traditional technological scheme, which includes crushing stages of the initial raw material, deproteinization, demineralization and deacetylation of obtained chitin [7].
TABLE I TOTAL CHEMICAL COMPOSITION OF CRAYFISH SHELL AND MUSHROOMS OF OYSTER KIND

\begin{tabular}{|l|c|c|c|c|c|}
\hline \multirow{2}{*}{$\begin{array}{l}\text { Object of } \\
\text { investigation }\end{array}$} & \multicolumn{5}{|c|}{ Mass share, \% } \\
\cline { 2 - 6 } & Moisture & Protein & Fat & $\begin{array}{c}\text { Carbohy } \\
\text { drate }\end{array}$ & Ash \\
\hline $\begin{array}{l}\text { Crayfish } \\
\text { (SCRM) }\end{array}$ & 64.54 & 11.43 & 0.45 & - & 13.97 \\
\hline $\begin{array}{l}\text { Shrimp } \\
\text { SCRM }\end{array}$ & 73.43 & 8.37 & 2.12 & - & 8.98 \\
\hline $\begin{array}{l}\text { Oyster } \\
\text { mushrooms }\end{array}$ & 89.22 & 1.67 & 0.52 & 6.78 & 0.81 \\
\hline
\end{tabular}

TABLE II. MUSHROOMS

\begin{tabular}{|l|c|}
\hline Object of investigation & Mass share of chitin, \% \\
\hline Crayfish (shell) & 9.61 \\
\hline Shrimp SCRM & 7.18 \\
\hline Oyster mushrooms & 0.52 \\
\hline
\end{tabular}

Technological efficiency in the use of SCRM of crawfish, shrimp, industrial waste recycling of mushrooms of the genus Pleurotus for food chitosan was assessed by the following indicators: the number of stages in the production of chitosan, the total duration of the process of obtaining chitosan and the product yield (table 3).

TABLE III. EVALUATION OF TECHNOLOGICAL EFFICIENCY OF DIFFERENT KINDS OF RAW MATERIALS

\begin{tabular}{|l|c|c|c|}
\hline \multirow{2}{*}{$\begin{array}{l}\text { Technological } \\
\text { parameters }\end{array}$} & \multicolumn{3}{|c|}{ Kind of raw materials } \\
\cline { 2 - 4 } $\begin{array}{l}\text { Quantity of stages } \\
\text { chitosan production }\end{array}$ & 3 & Crayfish & Mushroom \\
\hline $\begin{array}{l}\text { Total time of chitosan } \\
\text { production, h }\end{array}$ & 5 & 6.5 & 5 \\
\hline $\begin{array}{l}\text { Output of chitosan, \% } \\
\text { relatively mass share } \\
\text { of raw material }\end{array}$ & 5.03 & 4.91 & 7 \\
\hline
\end{tabular}

To intensify the production of chitin from the PCS of crustaceans, an approach involving electrohydraulic processing of raw materials by electrohydraulic shocks was used.

Electrohydraulic shock (EHU) is a phenomenon that makes it possible to convert electrical energy into mechanical energy without intermediate mechanical links.

In the case of implementation of electrohydraulic shock in the volume of the liquid which is in a tank under the influence of specially created pulse electric spark discharge around a zone of its formation, there are extreme hydraulic pressures, capable to make the useful mechanical operation and followed by a complex of the physical and chemical effects.

The technological capabilities of electrohydraulic shock are provided at the expense of super long discharges in the carrying-out liquids by the limit reduction of the active area of the positive electrode (that is adjoining to liquid). At the same 
time, increasing the active area of the negative electrode [9, $10]$.

The main role in the discharge process belongs to ion $\mathrm{H}^{+}$, $\mathrm{OH}^{-}$in the water in the presence of ions.

Existence and length of the channel of the category depend on the quantity of the electrons which are torn from ions of $\mathrm{OH}^{-}$and which join then in the channel of the category, define its existence and its length. At the same time, $\mathrm{H}^{+}$ion (or gidroksony $\mathrm{H}_{3} \mathrm{O}^{+}$) does not take part in growth of channels and, from this point of view, is useless for the entire process of the category.

In water between electrodes, there is a significant asymmetry of the field at a sharp decrease of the active, adjoining to water surface of a positive electrode (by its maximum isolation throughout the entire length, except the forward end) and a simultaneous sharp increase in an active surface of a negative electrode. The special ionic atmosphere (mainly one sign), promoting intensive germination of a streamer in liquid, is a consequence of it. Such asymmetry of the field creates in the area between electrodes favorable conditions for fast neutralization of ions of $\mathrm{H}^{+}$and enrichment of liquid $\mathrm{OH}^{-}$ions. Ions of $\mathrm{H}^{+}$are easily discharged on an extensive negative electrode whereas the minimum surface of a positive electrode complicates formation of new ions of $\mathrm{H}^{+}$. There is a sharp reduction of the total number of ions of $\mathrm{H}^{+}$in volume among electrodes. Liquid $\mathrm{pH}$ in this volume moves to the alkaline area.

At the same time, $\mathrm{OH}^{-}$ions receive easily new charges from an extensive negative electrode. They sate interelectrode space and are actively discharged, mainly on the channel growing from a positive electrode, but not on all isolated positive electrode. Between the electrodes, there is a negative space charge from $\mathrm{OH}^{-}$ions, which easily transfers its electrons to the growing channel of the spark discharge. The quantitative shift of the ionic balance toward the predominance of $\mathrm{OH}^{-}$ions corresponds to the Kohlrausz law [10].

The mechanism of the formation of an alkaline medium in an aqueous solution in the case of an electrohydraulic shock is shown in Fig. 3

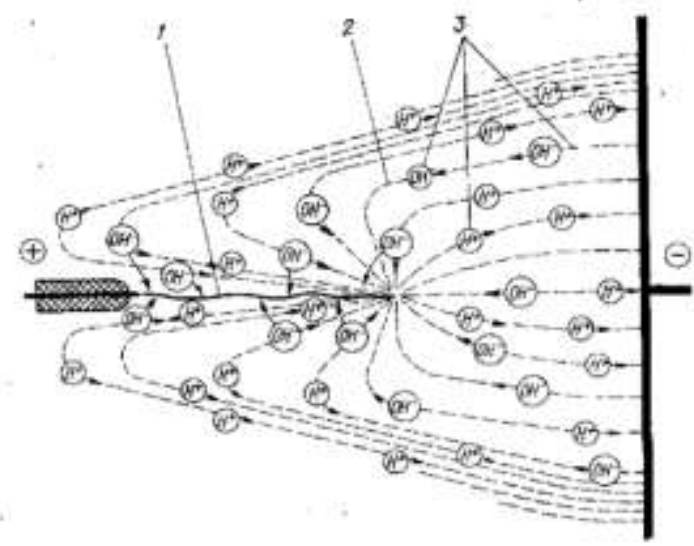

Fig. 3. The mechanism of the formation of an alkaline medium in solution during an electrohydraulic impact, where 1 is a growing streamer; 2 - field lines of force; 3 - direction of ion motion
The asymmetry of the field in the case of the occurrence of super long discharges creates favorable conditions in the region between the electrodes for the rapid neutralization of $\mathrm{H}$ + cations and for the enrichment of the liquid by hydroxyl anions $\mathrm{OH}^{-}$. As a result, an alkaline environment is formed in the solution, at which the $\mathrm{N}$-glycosidic bond is broken, due to which the chitin in the armature is bound to the protein. At the same time, the required degree of grinding is attained, in which the subsequent process of deacetylation of chitin proceeds uniformly throughout the mixture.

A high-frequency current is applied to the positively charged electrode, as a result of which a current breakdown occurs on a negatively charged electrode, accompanied by multiple EHGs and the formation of an alkaline medium. In the raw material, the protein component is crushed and removed.

To reproduce electrohydraulic impacts inside the volume of the mixture consisting of crustaceans and water in the ratio $1: 15$, the design of the plant is proposed, which includes a power source with a capacitor as a storage of electric energy (Fig. 4). This scheme is implemented in the original technical solution of the apparatus for producing chitin and chitosan (Fig. 5). The reactor is made in the form of a tank with a jacket installed on the base. Mounted in the reactor a removable perforated container of dielectric material for loading the processed raw materials and branch pipes for the input and output of process reagents.

For reproduction of the electrohydraulic shocks in the volume of the compound, consisting of the shell of crustaceans and water in the ratio of $1: 15$, the authors used the installation which operates using the source of energy with the condenser as the accumulator of electrical energy (Fig. 4).

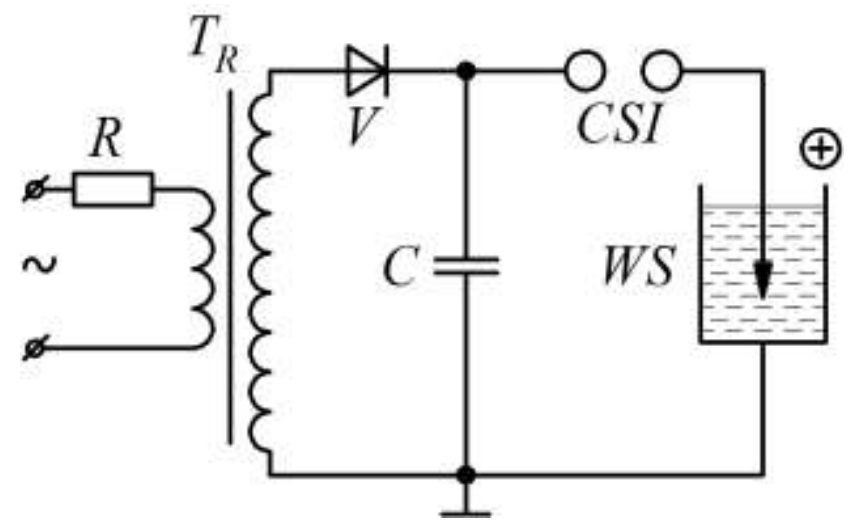

Fig. 4. An electric circuit of installation for reproduction of electrohydraulic shocks: $\mathrm{R}$ - charge resistance; $\mathrm{T}_{\mathrm{R}}$ - the transformer; V - rectifier; CSI - the creating spark interval; WS - a work space; $\mathrm{C}$ - the capacitor 


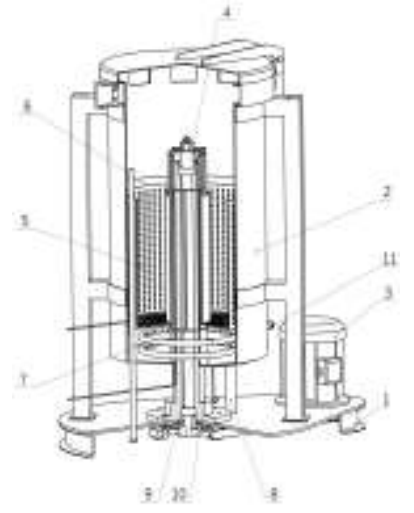

Fig. 5. General view of the installation for obtaining of chitin and chitosan: 1 - base box; 2 - reactor tankage; 3 - electric motor; 4 - vertical shaft; 5 perforated removable container; 6 - external negative electrode; 7 - central positive electrodes; 8 - drain pipe; 9, 10, 11 - the nozzles for supplying process mediafigure caption)

The authors established experimentally that the processing of shell crustaceans is advantageously to carry out with an average mode of operation of the electro-hydraulic setup, the capacitance of the capacitor $(\mathrm{C})=0.1 \mu \mathrm{f}$; voltage $\mathrm{U}=50 \mathrm{kV}$; the distance between electrodes $(\mathrm{l})=25 \mathrm{~mm}$; the temperature of the mixture $(\mathrm{t})=20^{\circ} \mathrm{C}$. As the result, there is a grinding shell crustaceans in suspension to a particle size of $0.05-0.1$ $\mathrm{mm}$. The resulting suspension is passed through a suction filter; the precipitate is placed in the reactor with a mixer and a shirt. The precipitate is treated with hydrochloric acid with volume fraction of $2-4 \%$ at the hydraulic module of $1: 10$, a temperature of $20-25{ }^{\circ} \mathrm{C}$ and stirring for $2 \mathrm{~h}$. Further, the solid and the liquid fraction were separated, the precipitate was washed with distilled water to $\mathrm{pH}$ 7.0. Depending on the kind of used shell crustaceans, a solution of sodium hydroxide with a mass fraction of $35-45 \%$ was added to the obtained chitin and the mixture was incubated at a temperature of $95-98{ }^{\circ} \mathrm{C}$ during 1-2 hours.

TABLE IV. PHYSICO-CHEMICAL CHARACTERISTICS OF CHITOSAN

\begin{tabular}{|c|c|c|c|}
\hline \multirow[b]{2}{*}{$\begin{array}{l}\text { Physico-chemical } \\
\text { characteristics of } \\
\text { chitosan }\end{array}$} & \multirow{2}{*}{$\begin{array}{l}\text { Chitosan from } \\
\text { carapace of crab } \\
\text { (producer is } \\
\text { "Bioprogress", } \\
\text { Schelkovo, } \\
\text { Moscow region) }\end{array}$} & \multicolumn{2}{|c|}{$\begin{array}{l}\text { Samples of chitosan } \\
\text { obtained by proposed } \\
\text { method }\end{array}$} \\
\hline & & $\begin{array}{l}\text { From } \\
\text { shell of } \\
\text { shrimp }\end{array}$ & $\begin{array}{l}\text { From } \\
\text { carapace of } \\
\text { freshwater } \\
\text { crayfish }\end{array}$ \\
\hline $\begin{array}{l}\text { Characteristic viscosity } \\
\text { (in the } 2 \% \text { solution of } \\
\text { acetic acid), } \mathrm{dl} / \mathrm{g}\end{array}$ & 25.0 & 24.1 & 22.9 \\
\hline Molecular mass, to & 260 & 300 & 270 \\
\hline $\begin{array}{ll}\text { Degree } & \text { of } \\
\text { deacetitisation, } \% & \\
\end{array}$ & 82 & 92 & 90 \\
\hline Mass share of ash, $\%$ & 0.7 & 0.4 & 0.5 \\
\hline Protein residue, $\%$ & 0.05 & 0.05 & 0.03 \\
\hline $\begin{array}{l}\text { Mass share of moisture, } \\
\%\end{array}$ & 9 & $9-10$ & $8-10$ \\
\hline $\begin{array}{ll}\text { Particle } & \text { size } \\
\text { (granulometrical } & \\
\text { composition), } \mathrm{mm} & \\
\end{array}$ & $0.1-0.2$ & $\begin{array}{l}0.05- \\
0.1\end{array}$ & $0.05-0.1$ \\
\hline
\end{tabular}

Chitosan which was received by electrohydraulic processing does not concede by physical and chemical indicators to the food chitosan received with use of acid-base reactants (tab. 4). At the same time, samples of chitosan possess identical spectral characteristics in the IR-area in the range of wave numbers of 4000-400 $\mathrm{cm}^{-1}$.

The rigid mode of processing of shell-containing raw materials on the apparatus, reproducing electrohydraulic impacts, leads to a rupture of intermolecular communications of chitosan, reduction of molecular weight, change of the supramolecular structure, the degree of crystallinity and to a decrease in viscosity of its solutions that limits possibilities of use of the received chitosan in the food industry.

An increase in capacity or reduction in case of the soft mode of processing of shell-containing raw material does not provide the energy of influence, sufficient for a rupture of communications between protein and chitin in its structure. It also leads to insufficient extent of its crushing that does not allow one to carry out the process of a deproteinate of chitosan along with crushing.

It is experimentally established that it is expedient to carry out processing of PSS of Crustacea at an average operating mode of electrohydraulic installation at which the rupture of $\mathrm{N}$-glycosidic of communication at the expense of which chitin in PSS is connected with protein is provided. Removal of a proteinaceous component results (deproteinization). Extent of crushing of PSS of Crustacea at which process of deacetylation of chitin proceeds evenly in all volume of mix is at the same time is reached.

Use of other modes of installation on reproduction of EGU leads to receiving chitosan of more poor quality, with lower molecular weight and non-uniform on the extent of deacetylation (ED) that limits its possibility of application in the food industry.

The offered mode of processing allows carrying out deacetylation in homogeneous conditions with a completely destroyed crystal structure of chitin and chitosan.

TABLE V. MICROBIAL ATTRIBUTES OF CHITOSAN

\begin{tabular}{|c|c|c|}
\hline Name of indicator & Threshold value & $\begin{array}{c}\text { Actual measure } \\
\text { value }\end{array}$ \\
\hline $\begin{array}{c}\text { Mesophilic aerobic and } \\
\text { facultative anaerobic } \\
\text { microorganisms, Units } \\
\text { forming colonies /g }\end{array}$ & $4 \times 10^{4}$ & $3.9 \times 10^{4}$ \\
\hline Coliform bacteria & Prohibited & Not discovered \\
\hline Pathogenic microorganisms & Prohibited & Not discovered \\
\hline $\begin{array}{c}\text { Mold fungi, Units forming } \\
\text { colonies /g }\end{array}$ & $2 \times 10^{4}$ & $1.7 \times 10^{4}$ \\
\hline
\end{tabular}

Homogeneous deacetylation leads to uniform deacetylation of $\mathrm{N}$-acetylated links on all length of a molecule and receiving chitosan, uniform in ED that positively influences its physical and chemical properties [9].

Advantages of this technical solution:

- combining the stages of grinding and deproteinization of chitin-containing raw materials;

- absence of alkaline reagents at the stage of deproteinization. 
The microbiological characteristics of chitosan, obtained by the proposed technology under laboratory conditions, were determined. Data are presented in Table 5.

Organoleptic characteristics of chitosan derived from shrimp shell by the developed technology in comparison with the commercial sample are presented in Table 6 .

TABLE VI. ORGANOLEPTIC PARAMETERS OF CHITOSAN

\begin{tabular}{|c|c|c|}
\hline Indicator name & \multicolumn{2}{|c|}{ Characteristics for samples of chitosan } \\
\cline { 2 - 3 } & $\begin{array}{c}\text { from carapace of crab (producer } \\
\text { is "Bioprogress", Schelkovo, } \\
\text { Moscow region) }\end{array}$ & $\begin{array}{c}\text { from shell of } \\
\text { shrimp }\end{array}$ \\
\hline Appearance & Scales 1-3 mm in size & $\begin{array}{c}\text { Scales 1-3 mm } \\
\text { in size }\end{array}$ \\
\hline Colour & Yellow & White \\
\hline Smell & No smell & No smell \\
\hline
\end{tabular}

Organoleptic characteristics of chitosan from shrimp shell is consistent the biopolymer obtained by the traditional method. The contrast of chitosan according to the traditional technology is the white color due to the presence in the production stage of bleaching.

For comparative characteristics of the structure of the polymer IR spectra of chitosan samples (Fig. 6) obtained from the shell of shrimp (the proposed technology) and crab (traditional technology) was removed.

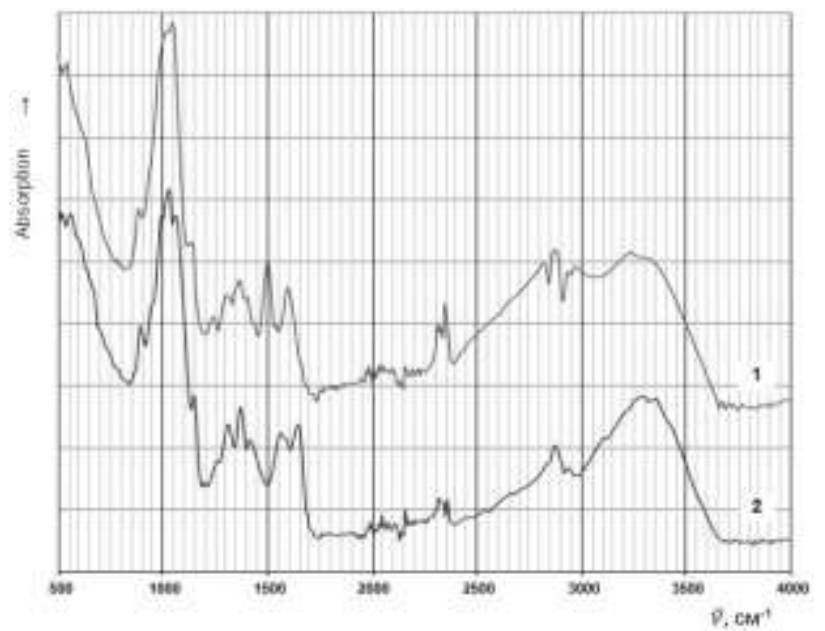

Fig. 6. IR-spectra of chitosan from the carapace of a crab, the manufacturer is the closed joint-stock company "Bioprogress" (1) and from the shell of shrimp (2)

Analysis of IR spectra, in general, showed both the identity of the chemical structure of the chitosan samples. But attention is drawn to the presence of a second sample in the spectrum absorption bands 1550-1560, $1650 \mathrm{~cm}^{-1}$ characteristic to a greater degree of oscillations of $\mathrm{NH}$-links of the primary amino groups, and their displacement in the long wavelength region for the first sample to 1510 and $1600 \mathrm{~cm}^{-1}$, corresponding to vibrations of secondary amide linkages. The presence of additional absorption peaks of $2820,2980 \mathrm{~cm}^{-1}$ in the spectrum of the first sample may be due to variations in the CH-bond methyl acetyl groups of chitin fragments. Thus, these data indicate incomplete deacetylation of chitin in the preparation of the sample 1 by the acid-alkali treatment.
To use the chitosan substances in various branches they have to possess the specific physical, chemical and functional properties. In this regard, the actual task is to develop the means and methods of control of target parameters, key of which are qualitative identification and quantitative determination of chitosan in the composition of the functional compositions and products with their use. As the chromophore to measure the surface potential of the chitosan substances, we used 1-aniline-8-naphthalenesulfonate (ANS). The maximum fluorescence of the dye in chitosan films is shifted to longer wavelengths compared to chitosan gels, because of the increased polarity of the medium of films on the attitude to gel-like chitosan substances [11]. The data obtained with the use of fluorometric studies can be used in the development of methods for the detection of chitosan.

The results indicate that for the production of food chitosan is technologically better to use SCRM shrimp in comparision with other sources. This is actual for regions that are geographically distant from traditional and new basins of the king crab catch.

Testing of chitosan was performed in the concentration range from 1 to $4 \%$ for multicomponent forcemeat systems for meatballs and schnitzels with a ratio the price - quality oriented on consumers with average income. It was investigated the effect of chitosan on functional and technological properties of meat model systems - waterbinding capacity (WCC), water-holding capacity (WHC), fatholding ability (FHA), emulsifying ability (EA) and emulsion stability (ES). In model meat systems we used the stuffing from one-grade beef and pork chopping on the mincer with a hole diameter of the lattice $2-3 \mathrm{~mm}$ at the following ratio: $2: 1$ for meatballs, 5:4 for schnitzel.

These functional properties of chitosan from SCRM shrimp allow to consider it as perspective functionalcorrective component of food products. The introduction of chitosan into the water, which does not interact chemically with it, provides a rapid swelling of the polymer, and every bit of chitosan swells separately from the others and the resulting mass (Sol) is homogeneous (free of lumps). It was established that chitosan from shrimp shell has a fast swelling properties: water absorption was $10.9 \mathrm{~cm}^{3} / \mathrm{g}$ for $4-5$ minutes. The fact that chitosan of shrimp SCRM is a hydrocolloid, determines its potential functionality processing for food purposes of livestock products in branches of meat, fish and dairy industries.

The authors have established that chitosan improves functional and technological properties (FIP) of meat systems. Values of the FIP model stuffing for meatballs and schnitzels had no significant differences. The nature of the effect differed for individual indicators. So, the WCC has increased by $20 \%$ on average for the tested systems at the concentration of chitosan $2 \%$, a further increase did not give significant effect. WBC increase was $14.5 \%$; stabilization of this indicator occurred at $3 \%$ of chitosan. FHC increased by 21.7 and $22.7 \%$; EA - $26.05 \% 23.11 \%$ for model force meat of meatballs and schnitzels, respectively, when the mass fraction of chitosan $4 \%$. Similar results were obtained for the stability of emulsions, it increased by 26.1 and $23.1 \%$. 
In the next phase of research were defined organoleptic characteristics of molded film from model forcemeat of meat products after cooking. The addition of chitosan in the amount of $1 \%$ does not affects the organoleptic characteristics, $3 \%$ leads to a slight deterioration of taste, and the dose increased to $4 \%$ leads to considerable deterioration.

\section{CONCLUSIONS}

The authors have developed an alternative technical approach to obtaining chitosan from crustacean shell. It is designed to combine the stages of grinding and deproteinization, avoids the use of alkali at the stage of deproteinization using electro-hydraulic shock is carried out using extra-long bits. The proposed method of obtaining chitosan has the following advantages: the possibility of organizing the recycling process of shells crustaceans on the production base of processing of the main raw material; reducing the consumption of alkaline and sewage of the volume of waste water through the use of electro-shock at the stage of the deproteinization.

By the combining of the processes of grinding and deproteinization of the shells of crustaceans, it is possible to reduce the total duration and labor input of the process, to improve the ecological state of the production.

Thus, it can be concluded that the chitosan obtained by electro-processing is not inferior in its physical and chemical indicators from the samples of chitosan obtained with traditional alkaline reagents. The chitosan which was received through the electrohydraulic processing does not concede to the food chitosan received with use of acid-base reactants by physical and chemical indicators. At the same time, the samples of chitosan possess identical spectral characteristics in the IR-area in the range of wave numbers of $4000-400 \mathrm{~cm}^{-1}$. By the results of researches, the indicators of quality and safety of the experimental samples of chitosan, it is possible to draw a conclusion on expediency of its use in foodstuff technologies.

\section{References}

[1] W. Xia "Biological activities of chitosan and chitooligosaccharides", Food Hydrocolloids, doi:10.1016/j.foodhyd.2010.03.003.

[2] M. N. A. Hasaneen, H. M. M. Abdel-Aziz, D. M. A. El-Bialy and Aya M. Omer «Preparation of chitosan nanoparticles for loading with NPK fertilizer», African Journal of Biotechnology, Vol. 13(31), p.3158-3164, 2014.

[3] V.E.Tikhonov, E.A. Stepnova, V.G. Babak, I.A.Yamskov, J. PalmaGuerrero, H.-B. Jansson, L.V. Lopez-Llorca, J. Salinas, D.V. Gerasimenko, I.D. Avdienko, V.P. Varlamov "Bactericidal and antifungal activities of a low molecular weight chitosan and its $n-/ 2(3)-$ (dodec-2-enyl)succinoyl/-derivatives", Carbohydrate Polymers,T. 64, vol 1, p. 66-72, 2006.

[4] G.Vikhoreva, P. Stolbushkina, L.Gal'braikh, G. Bannikova, V. Varlamov, A. Panov, N. Drozd, V. Makarov "Preparation and anticoagulant activity of a low-molecular-weight sulfated chitosan", Carbohydrate Polymers, T. 62. vol. 4. p. 327-332, 2005.

[5] I. Munoz, C. Rodríguez,2 D. Gillet,, B. M. Moerschbacher ,"Life cycle assessment of chitosan production in India and Europe", Int J Life Cycle Assess, 2017, DOI 10.1007/s11367-017-1290-2.

[6] Ilyina A.V., Varlamov V.P., Tikhonov V.E., Albulov A.I. Enzymic preparation of acid-free-water-soluble chitosan, Process Biochemistry. 2000, T. 35,. vol 6. p. 563-568.

[7] Gartman O., Vorobyeva V. (2013). Technology and properties of chitosan from the gammarus. Fundamental research, No 6-5, pp. 11881192.

[8] G. Kasyanov, E. Kubenko "The development of technology of obtaining chitosan from shell of gammarus crustacean's of the Azov. News of higher educational institutions", Food technology, vol. 1 (331), p. 69-72, 2013.

[9] I. Glotova, N.Vekshin, V. Balabaev, O.V. Peregonchaya, E. Kurchayeva "Preparation and properties of chitosan from crab shell containing raw material by electrophysical processing", Agrofor, T. 1, vol. 3. p. 89-96, 2016

[10] Yutkin L., Electrohydraulic effect and its application in industry. Mashinostroenie, Leningradbranch, Leningrad, 1986

[11] Vekshin N., Glotova I., Balabaev V., Izmailov V. "Fluorometric investigation of film-forming substances of chitosane", Fundamental research, vol. 6-3, p. 447-451, 2015. 